\title{
The Impact of Contraceptive use on Women Health: A Study of Rural Area, Minia, Egypt
}

\author{
Ebtesam Esmail Hassan ${ }^{1}$, Ekhlass M.Eltomy ${ }^{2}$, Mona Abuzeid Khalefa ${ }^{3}$ \\ ${ }^{1}$ Assistant Professor at Department of Public Health and Preventive Medicine, Faculty of Medicine, Minia \\ University, Minia, Egypt, ${ }^{2}$ Lecturer at Department of Community Health Nursing, Faculty of Nursing, Minia \\ University, Minia, Egypt., ${ }^{3}$ Professor at Department of Public Health and Preventive Medicine, Faculty of \\ Medicine, Minia University, Minia, Egypt
}

\begin{abstract}
Background: Women's health concerns are associated with the female reproductive system, breast and other physiological structures. Contraception was a deliberate and willful selection of contraceptive methods. In Egypt, there is an increasing trend of using contraception to regulate births due to recent awareness of contraception. However; having insufficient knowledge about use of contraceptives would be more risky and its prolonged use sometimes results in various health problems. Aim was to reveal the prevalence of contraception use in rural area of Minia governorate and study the most common health problems among user as compared to non-users. Methodology: cross sectional community based study conducted among 564 rural married women in reproductive age during the period from November 2018 to May 2019. Results: Nearly $69.1 \%$ of women were currently using a contraceptive method, 142 (25.2\%) never previously use contraception and $32(5.7 \%)$ discontinued. There were significant increase of health problem among currently contraception user a compared to currently non user, majority $(90.3 \%)$ of user complain menstrual irregularities compared to $24.1 \%$ of non-user ( $\mathrm{p}=0.003 * \mathrm{RR}=29.1$ ), $64.1 \%$ had nausea compared to $28.1 \%$ among non-user with $R R=6.3$, hypertension $(R R=5.5)$ Headache $(R R=2.6)$ Heart burn $(R R=3.3)$ had significant increased relative risk. Conclusion: The present study illustrates that contraceptive methods have important health impacts. Health states decrease the effectiveness of any method. Awareness should be enhanced by health education using mass media and counseling, male contraceptives should be introduced, medical free camps and contraceptive availability.
\end{abstract}

Keywords: Contraception Prevalence, Health impact, rural Minia, Egypt

\section{Introduction}

Pregnancy and contraceptive methods both have essential health impact that includes risks and benefits. Contraceptives are a thoughtful and premeditated selection of a birth control technique or set of techniques (1). Every method of contraception dominates nonuse in most clinical settings. The percentage of the need for family planning satisfied by modern methods, Sustainable Development Goals (SDG) indicator 3.7 .1 , was $75.7 \%$ globally in 2019 , yet less than half of the need for family planning was met in Middle and Western Africa ${ }^{(2)}$. Increasing the rate of using more effective methods will improve health and decrease costs. Long term methods that not necessitate action on daily basis are both less costly and more effective than ones requiring daily action by users ${ }^{(3)}$.

Effectiveness of contraceptive methods is influenced by socio-economic characteristics of the user and contraceptive method itself. Enhancing health awareness of women in choosing a method based on need necessitate careful assessment of women characteristics. A number of factors attribute to the woman characteristics and influence a women's likelihood for suitable family planning method use. Life stage, demographic data, educational level, daily tasks, and nature of job are among the variables a provider needs to evaluate before selecting a recommended family planning method to a user. Health problems, religious and cultural beliefs, past experience with family planning methods have a 
crucial role in selection and effectiveness of any family planning methods ${ }^{(1)}$.

In Egypt, Since 1990, the total fertility rate (TFR) has been slowly decreasing, from 4.1 in 1991 to 3.5 in 2000 and 3.0 in 2008, but it unexpectedly increased to 3.5 in the Egypt 2014(4). From 2008 till 2014, the rate of family planning use slightly decreased from $60 \%$ to $58 \%$.

The rate of intrauterine device users decreased from $36 \%$ to $30 \%$, and the rate of pill users elevated from $12 \%$ to $16 \%$. The United Nations Development Program (UNDP) reported that "with the current drop in family planning methods usage rate, it is unexpected for Egypt to locally or nationally achieve the MDG target relating to a family planning prevalence rate of $72 \%$, which is essential to achieve the total fertility rate (TFR) of 2.1 children per woman by $2015^{(5)}$.

Accordingly, the Strategic National Population Plan 2015-2030 in Egypt has asked for urgentstrategies to decrease the TFR to 2.4 births per woman by the year 2030. Total fertility rate can be reached by elevating family planning methods prevalence from 58\% in 2014 to $72 \%$, decreasing the rate of discontinuation (in the first year of use) from $30 \%$ in 2014 to $18 \%$, and decreasing the percentage of unmet need for contraceptive methods from $13 \%$ to $6 \%$. To achieve this aim, the contraceptive programs must safeguard high quality services for the provision of family planning methods and assure favorable attitudes toward the initiation and continuation of family planning methods. Though, this aim should be evaluated as aspirant, taking into consideration the elevating cost of assuring secure family planningmethods due to the large increase in Egypt's census ${ }^{(6)}$.

The trend of the discontinuation rate after the first year of usage in Egypt decreased from 30\% in 2000 to $26 \%$ in 2008 but then clearly elevated to $30 \%$ in 2014, This is estimated by constructing a life table to calculate the likelihood of stopping the use of family planning method during first year of initiation, estimated during a period of five years before the study. Also, the proportion of users who had method failure within first year of initiation was 3\% in 2008 and elevated to $4 \%$ in $2014^{(4)}$.
Recognizing the factors affecting discontinuation of contraceptive use is crucial to ensuring that users can achieve the long-term fertility desires. Previous studies on the determinants of contraceptive discontinuation has concentrated on socio-demographic characteristics and fertility motivations of users, the quality of family planning services or the family planning service environment, and the experience of side effects while using a method ${ }^{(7)}$. This is considered crucial conclusion that concentrate on highlighting, regions or sub-region, the used methods and user characteristics that may be necessary for improvements in policies and programs to address the elevated rates of contraceptive failure and discontinuation $^{(8)}$.

Demographic characteristics of women are set to be associated with stopping the use of methods its failure. In Egypt, all studies searched discontinuation rates aligned them with characteristics of women; discontinuation rate was raised among women of rural residence, the poorest and illiterate women. Also, studies illustrated that poorer, younger and illiterate women with one child living in rural Upper Egypt are more risky to stop contraceptive method though the desire to have contraceptive method without using another method ${ }^{(9)}$. The trend of the discontinuation rate after the first year of usage in Egypt decreased from 30\% in 2000 to $26 \%$ in 2008 then elevated to $30 \%$ in $2014{ }^{(6)}$.

\section{Study design and population}

A cross-sectional research design was performed on married women aged 18 - 49 years (reproductive age) during the period from November 2018 to May 2019 in a rural residence in Minia governorate. A multistage random sample was used as Minia governorate was divided into 9 districts from which Minia district was selected by simple random sample then Minia district was classified into villages from which Tala village was selected also by a simple random method.

\section{Setting:}

Avillage called Talaat Minia district of Minia governorate of Upper Egypt.

\section{Study population}

The participant women were selected by using a systematic random sample from the village (the 1st 
house was chosen randomly then every 3 rd house).

The sample size was calculated using EP Info version 7. A total of 564 women at reproductive age (1545 years), were participated in this study.

A total of 180 students at reproductive age (15-25 years) were interviewed.

\section{Inclusion criteria:}

-Currentlyusersof family planning methods

- Currently non-users of family planning methods

\section{2- Exclusion criteria:}

Women who stopped using contraception because

- Their husbands are working abroad.

- Women who had hysterectomy or pregnant women.

\section{Data collectionprocedures:}

The sample was selected through the following process:

- Researchers interviewed the participant women directly during their visit to the maternal health center for therapeutic or preventive purposes as family planning or child vaccination etc.

Researchers interviewed the participant women indirectly by obtaining the addresses of them from the allocated rural health unit and with the aid of rural health pioneer called RadatRefeat and they reached to them by home visit.

\section{Instruments for Data Collection}

Data were collected by adopting a designed interviewing questionnaire.The original form was the client medical and nursing record called client form available at Rural Health Facilities of the Egyptian ministry of health. The questionnaire consisted of two parts; 1) Demographical data: it contained questions related to socio economic domains such as educational level, age, occupation and family income.

2. Contraceptive practice: this part included questions about currently used methods; duration of use previously used method and cause of changing this method.

3- Medical history: this part included the most common health problems considered as an effect of family planning use included menstrual irregularities, headache, nausea, heart burn, vaginal discharge, mood changes, hypertension, weight change, DM and depression.

\section{Validity:}

The questionnairewas revised for content validity by a five of experts in the field of Community Health Nursing and Public Health Medicine.

Reliability: The researchers examined the internal consistency of the instrument. It is the administration of the same tools to the same subjects under similar circumstances on one or more occasions. Cronbach's $\alpha$ for of the questionnaire was 0.76 .

\section{Ethical consideration}

An approval was obtained from the research ethical committee of the authors' institutions (faculty of Medicine and Nursing). Another approval was obtained from the local council of Tala village to interview the participants. Following the ethical rules of epidemiological research, a written informed consent was obtained from the participant women included the aim, the nature of the study and ascertaining confidentiality of the information. Each participant was interviewed individually to fulfill the necessary data and informed of having the choice to withdraw from the study at any time.

\section{Statistical Analysis}

After completion of data collection, data entry was done. Then data were coded, analyzed using Statistical Software Packages "SPSS" version 21.

Quantitative data were presented in the form of mean and standard deviation; qualitative data were presented as frequency distribution. Independent sample $t$ test and chi square test were used. Relative risk (RR) was estimated and logistic regression analysis was used. Statistical significance was set at $\mathrm{p}<0.05$. 


\section{Results}

Of the 564 women surveyed, 390 women (69.1\%) were currently using a contraceptive method, $142(25.2 \%)$ never previously use contraception and 32 (5.7\%) discontinued (figure1).

The socio-demographic characteristics of the studied women are presented in Table 1 . Women who currently use contraception had a significantly lower marital age (18.7 \pm 3.5 vs. $19.9 \pm 8.2)$. About $54 \%$ of women with no contraception use were $\geq 35$ years of age. About $61.5 \%$ of women who currently use contraception their family income was enough but not safe. .No other statistically significant differences were found for other sociodemographic factors such as education and employment of both wife and husband.

Characteristics of women currently use contraception are described in Table 2, currently used contraceptive methods were distributed as following $44.1 \%$ use contraceptive pills, $28.7 \%$ use injections, $15.4 \%$ use
IUD $8.7 \%$ use capsule and $3.1 \%$ use local methods. There was $51.8 \%$ of participant use another before the current one, these used methods were pills $(14.9 \%)$, injections (26.7\%), IUD (24.8\%), capsules (8.9\%) and local methods (24.8\%). Reasons for changing method are experiencing health problems $(60.4 \%)$, Contraceptive failure (19.8\%) and forgetting pills (19.8\%).

Figure 2 showing that menstrual irregularities was the most prevalent $(69.9 \%)$ health problems among the studied females followed by headache (54.6\%), Nausea (51.1\%), heart burn (42.9\%). Vaginal discharge (38.3\%), mood changes $(36.5 \%)$ hypertension $(34.8 \%)$,

From tables it was found that significant increase of health problem among currently contraception user as compared to currently non user, majority (90.3\%) of user complain menstrual irregularities compared to $24.1 \%$ of non-user $(\mathrm{p}=0.003 * \mathrm{RR}=29.1), 64.1 \%$ had nausea compared to $28.1 \%$ among non-user with $\mathrm{RR}$ $=6.3$, hypertension $(R R=5.5)$ Headache $(R R=2.6)$ Heart burn $(R R=3.3)$ had significant increased relative risk.

Table 1:Socio-demographic characteristics of the studied women:

\begin{tabular}{|c|c|c|c|c|}
\hline & $\begin{array}{c}\text { Currently Users } \\
\qquad \mathbf{N}=\mathbf{3 9 0}\end{array}$ & $\begin{array}{c}\text { Currently Non Users } \\
\qquad \mathrm{N}=174\end{array}$ & $\begin{array}{l}\text { to } \\
\chi^{2}\end{array}$ & $\mathbf{P}$ \\
\hline $\begin{array}{l}\text { Age (years): } \\
<25 \text { years old } \\
25-34 \text { years old } \\
\geq 35 \text { years old } \\
\text { Mean } \pm \text { SD }\end{array}$ & $\begin{array}{c}52(13.3 \%) \\
204(52.3 \%) \\
134(34.4 \%) \\
31.6 \pm 7.1\end{array}$ & $\begin{array}{c}26(14.9 \%) \\
54(31 \%) \\
94(54 \%) \\
35.5 \pm 11.03\end{array}$ & $\begin{array}{l}23.6 \\
5.10\end{array}$ & $\begin{array}{l}0.001 * \\
0.001 *\end{array}$ \\
\hline $\begin{array}{c}\text { Age at marriage } \\
\text { Marital period } \\
\text { Number of children } \\
\text { Number of pregnancy } \\
\text { Number of abortions }\end{array}$ & $\begin{array}{c}18.7 \pm 3.5 \\
12.6 \pm 7.2 \\
3.3 \pm 1.2 \\
4.01 \pm 4.3 \\
1.6 \pm 1.01\end{array}$ & $\begin{array}{c}19.9 \pm 8.2 \\
15.4 \pm 19.8 \\
3.3 \pm 1.8 \\
3.7 \pm 2.2 \\
1.5 \pm 0.7\end{array}$ & $\begin{array}{l}2.3 \not \\
3.5 \propto \\
0.26 \propto \\
0.71 \propto \\
0.78 \propto\end{array}$ & $\begin{array}{c}0.01^{*} \\
0.01^{*} \\
0.7 \\
0.4 \\
0.4\end{array}$ \\
\hline $\begin{array}{c}\text { Women's education: } \\
\text { Illiterate } \\
\text { Basic } \\
\text { Secondary } \\
\text { University/above }\end{array}$ & $\begin{array}{c}148(37.9 \%) \\
202(51.8 \%) \\
34(8.7 \%) \\
6(1.5 \%)\end{array}$ & $\begin{array}{c}80(46 \%) \\
74(42.5 \%) \\
18(10.3 \%) \\
2(1.1 \%)\end{array}$ & 4.5 & 0.2 \\
\hline $\begin{array}{c}\text { Women's occupation: } \\
\text { Housewife } \\
\text { Works }\end{array}$ & $\begin{array}{c}352(90.3 \%) \\
38(9.7 \%)\end{array}$ & $\begin{array}{c}162(93.1 \%) \\
12(6.9 \%)\end{array}$ & 1.2 & 0.2 \\
\hline
\end{tabular}


Cont... Table 1:Socio-demographic characteristics of the studied women:

\begin{tabular}{|c|c|c|c|c|}
\hline $\begin{array}{c}\text { Husband age } \\
\text { Mean } \pm \text { SD }\end{array}$ & $36.1 \pm 8.8$ & $35.8 \pm 15.8$ & 0.30 & 0.7 \\
\hline Husband's occupation: & & & 1.1 & 0.8 \\
\hline Farmer & $98(25.1 \%)$ & $40(23 \%)$ & & \\
\hline Unemployed & $32(8.2 \%)$ & $16(9.2 \%)$ & & \\
\hline Manual & $16(4.1 \%)$ & $10(5.7 \%)$ & & \\
\hline Technician & $200(51.3 \%)$ & $88(50.6 \%)$ & & \\
\hline Professional work & $44(11.3 \%)$ & $20(11.5 \%)$ & & \\
\hline Husband's education: & & & 0.37 & 0.8 \\
\hline Illiterate & $100(25.6 \%)$ & $46(26.4 \%)$ & & \\
\hline Secondary & $238(61 \%)$ & $108(62.1 \%)$ & & \\
\hline University/above & $52(13.3 \%)$ & $20(11.5 \%)$ & & \\
\hline Family income & & & 14.1 & $0.001^{*}$ \\
\hline Not enough & $84(21.5 \%)$ & $58(33.3 \%)$ & & \\
\hline Enough but not safe & $240(61.5 \%)$ & $78(44.8 \%)$ & & \\
\hline Enough & $66(16.9 \%)$ & $38(21.8 \%)$ & & \\
\hline
\end{tabular}

${ }^{*}$ Significant. N.B. Currently no user is including ever no user $(\mathrm{n}=142)$ and previously user and discontinued $(\mathrm{n}=32)$

Table 2: Characteristics of currently user women (number=390):

\begin{tabular}{|c|c|c|}
\hline Variable & Frequency & $\%$ \\
\hline $\begin{array}{c}\text { Currently used method } \\
\text { Pills } \\
\text { Injections } \\
\text { IUD } \\
\text { Capsules } \\
\text { Local methods }\end{array}$ & $\begin{array}{c}172 \\
112 \\
60 \\
34 \\
12\end{array}$ & $\begin{array}{c}44.1 \\
28.7 \\
15.4 \\
8.7 \\
3.1\end{array}$ \\
\hline $\begin{array}{l}\text { Duration of use (year) } \\
\text { Range } \\
\text { Mean } \pm \text { SD }\end{array}$ & & \\
\hline $\begin{array}{l}\text { Changing the method } \\
\text { Yes } \\
\text { No }\end{array}$ & $\begin{array}{l}202 \\
188\end{array}$ & $\begin{array}{l}51.8 \\
48.2\end{array}$ \\
\hline $\begin{array}{c}\text { Previously used method } \\
\text { Pills } \\
\text { Injections } \\
\text { IUD } \\
\text { Capsules } \\
\text { Local methods }\end{array}$ & $\begin{array}{c}202 \\
30 \\
54 \\
50 \\
18 \\
50\end{array}$ & $\begin{array}{r}100 \\
14.9 \\
26.7 \\
24.8 \\
8.9 \\
24.8\end{array}$ \\
\hline $\begin{array}{c}\text { Reasons for changing method } \\
\text { Health problems } \\
\text { Contraceptive failure } \\
\text { Forgetting pills } \\
\end{array}$ & $\begin{array}{c}202 \\
122 \\
40 \\
40 \\
\end{array}$ & $\begin{array}{l}60.4 \\
19.8 \\
19.8 \\
\end{array}$ \\
\hline
\end{tabular}

$\mathrm{Nb}$. Local methods (vaginal cap ,condom) 
Table 3: Comparison between contraception users and non users regarding recently occurred health problem:

\begin{tabular}{|c|c|c|c|c|c|}
\hline Variables & $\begin{array}{l}\text { Currently Users } \\
\qquad \mathbf{N}=\mathbf{3 9 0}\end{array}$ & $\begin{array}{c}\text { Currently } \\
\text { Non users } \\
\quad \mathrm{N}=174\end{array}$ & $\mathbf{Z}$ & $\begin{array}{c}\text { RR } \\
(95 \% \mathrm{CI})\end{array}$ & $P$ for $R R$ \\
\hline Nausea & $250(64.1 \%)$ & $38(21.8 \%)$ & $9.2(0.009 *)$ & $\begin{array}{c}6.3 \\
(4.2-9.6) \\
\end{array}$ & $0.001 *$ \\
\hline Hypertension & $174(44.6 \%)$ & $22(12.6 \%)$ & $7.4\left(0.006^{*}\right)$ & $\begin{array}{c}5.5 \\
(3.4-9.1)\end{array}$ & $0.001 *$ \\
\hline Headache & $242(62.1 \%)$ & $66(37.9 \%)$ & $5.3\left(0.005^{*}\right)$ & $\begin{array}{c}2.6 \\
(1.8-3.8) \\
\end{array}$ & $0.001 *$ \\
\hline Mood change & $150(38.5 \%)$ & $56(32.2 \%)$ & $1.4(0.07)$ & $\begin{array}{c}1.2 \\
(0.9-1.9) \\
\end{array}$ & 0.1 \\
\hline Heart burn & $200(51.3 \%)$ & $42(24.1 \%)$ & $6.2(0.008 *)$ & $\begin{array}{c}3.3 \\
(2.2-4.9)\end{array}$ & $0.001 *$ \\
\hline vaginal discharge & $158(40.5 \%)$ & $58(33.3 \%)$ & $1.6(0.05)$ & $\begin{array}{c}1.3 \\
(0.9-1.9) \\
\end{array}$ & 0.1 \\
\hline Depression & $94(24.1 \%)$ & $40(23 \%)$ & $0.2(0.3)$ & $\begin{array}{c}1.06 \\
(0.6-1.6) \\
\end{array}$ & 0.7 \\
\hline Menstrual Irregularity & $352(90.3 \%)$ & $42(24.1 \%)$ & $15.7(0.003 *)$ & $\begin{array}{c}29.1 \\
(17.9-47.1) \\
\end{array}$ & $0.001 *$ \\
\hline Increased weight & $94(24.1 \%)$ & $44(25.3 \%)$ & $0.2(0.3)$ & $\begin{array}{c}0.9 \\
(0.6-1.4) \\
\end{array}$ & 0.7 \\
\hline Decreased fertility & $132(33.8 \%)$ & $26(14.9 \%)$ & $4.6(0.001 *)$ & $\begin{array}{c}2.9 \\
(1.8-4.6)\end{array}$ & $0.001 *$ \\
\hline $\mathrm{DM}$ & $12(3.1 \%)$ & $10(5.7 \%)$ & $1.1(0.1)$ & $\begin{array}{c}0.51 \\
(0.22-1.2)\end{array}$ & 0.1 \\
\hline
\end{tabular}

\section{RR (Relative risk)}

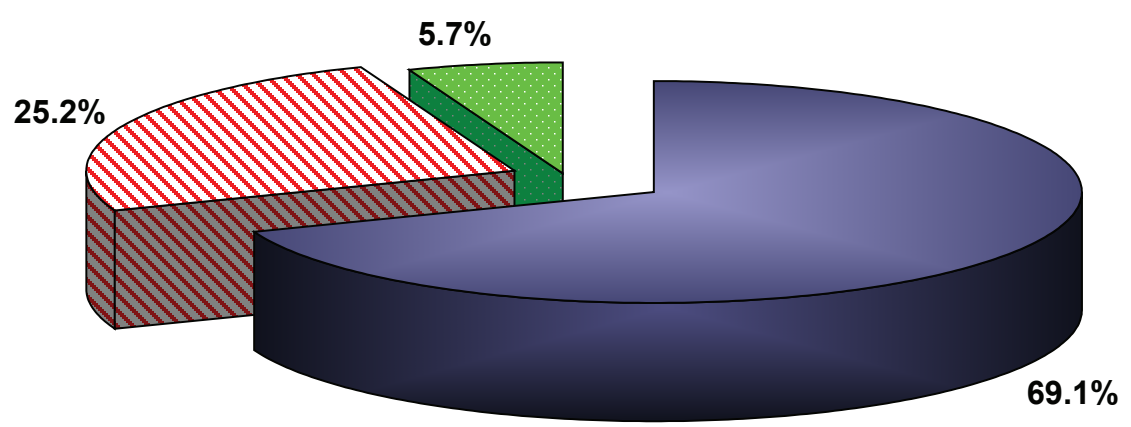

Currently Users $\triangle$ Never previously use $\square$ Discontinued

Figure 1:Prevalence of family planning use among study participants. 


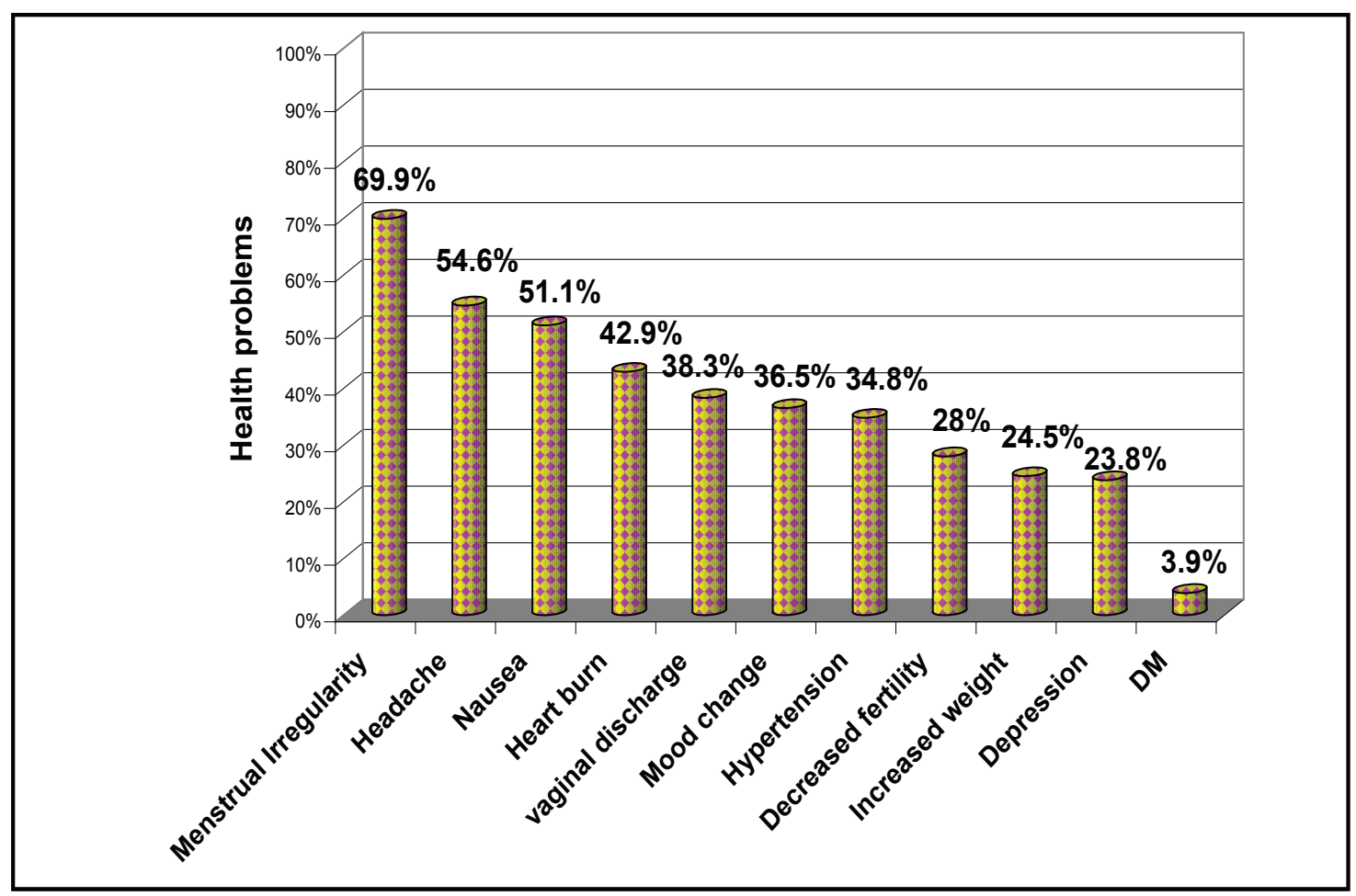

Figure 2:Distribution of the studied participant regarding prevalence of recently occurred health problem

\section{Discussion}

Prevalence of family planning use among study participants:

Family planning is crucial for women and families health, as it able to enhance the development of the country toward decreasing poorness and fulfilling growth goals. An increasing percent of women at Arabic countries are using contraceptive methods, as contraceptive services have broadened. Unmet need still not covered or satisfied ${ }^{(\mathbf{1 0})}$.

The current study revealed that Of the 564 women surveyed, 390 women (69.1\%) were currently using contraception, quarter of them never previously use contraception and the minority (5.7\%) discontinued. Which was similar to ${ }^{(11)}$ who studied "Currently Married Women with an Unmet Need for Contraception in Minia Governorate, Egypt: Profile and Determinants" found that $66.7 \%$ were currently relying on a family planning method.

Worldwide in 2017, $63 \%$ of women were using some form of contraception. Family planning methods use was above seventy percent in Europe, Latin America and the Caribbean, and Northern America, while being below quarter in Middle and Western Africa ${ }^{(\mathbf{1 2})}$.

These results are similar to report of ${ }^{(\mathbf{1 3})}$ who stated that though contraceptive methods elevated significantly both nationally and regionally it was still lesser than the goal of $74.7 \%$ targeted for the year 2020 instead of the current $(58.5 \%)$, to decrease the fertility rate from 3.5 child per woman to 2.1 child as the percent of discontinuation after first year is $30.1 \%$ to be decreased to $15 \%$ by 2020 . Also, ${ }^{(14)}$ studied "family planning methods use among Egyptian women" found that the prevalence of contraception was $57.5 \%$.

Researchers suggest that the increase in contraception may be associated with the expanding contraceptive services coverage and increasing health awareness. Also, the difference is present in the never previously use $(25.7 \%)$ and the discontinued women non-use percent $(5.7 \%)$ to be $30 \%$ as a total ${ }^{(4)}$.

The socio-demographic characteristics of the participant women: 
The present study results revealed the sociodemographic characteristics of the participants. Women who currently use contraception had a significantly lower marital age than non- users (18.7 \pm 3.5 vs. $19.9 \pm 8.2)$. More than half of non- users were $\geq 35$ years old. About two thirds $(61.5 \%)$ vs. two fifths $(44.8 \%)$ of users and non- users respectively have enough but not safe family income revealing statistically significant difference. No other statistically significant differences were found for other socio-demographic factors such as education and employment of both wife and husband.

These result was in agreement with ${ }^{(\mathbf{1 5})}$ who studied "factors affecting the family planning methods used by the currently married women in rural Egypt " found that $66.7 \%$ of users lied in the age group $40-49$ years, $80.9 \%$ having marital age $10-19$ year, and $64.6 \%$ their age of marriage above 18 year.

The results of the present study are similar to ${ }^{(4)}$ who reported that discrepancies in the usage rates are comparatively small by enhancing awareness among groups. Use rates are the identical for non-educated women representing fifty nine percent and a secondary or higher education participants representing sixty percent. Primary or secondary educated women are the least candidates for currently method use representing fifty five percent. Users occupied in paid cash work are more probably to use a method than non-users representing sixty seven percent and fifty seven percent, respectively. In the normal circumstances, secondary educated and paid cash job women or those having medium or higher affluence desired less than three children.

The current study results were in agreement with ${ }^{(\mathbf{1 6})}$ whoreported thatfactors affecting family planning use include access to integrated primary healthcare centers, marital age, socioeconomic status, and parity.

The present study results is convenient with ${ }^{(17)}$ who studied "Prevalence and correlates of contraceptive use among female adolescents in Ghana", reported that mother age, marital status, number of children born were all definitely associated with family planning methods use.

The results of the present study are relevant to ${ }^{(\mathbf{1 8})}$ who studied Emergency contraceptive pill use among women of reproductive age in Myanmar reported that, among candidates from Brazil, Chile and Mexico possessing a low income contradicted with their contraceptive use. This was attributed to lack of knowledge. Also, the idea of motherhood is the personality and fate of a woman which made them feeling do not need contraceptive methods is reported as a barrier among low-income women. Higher income women had better access to information about contraceptive methods. Also, awareness about the available places to buy family planning methods with better accessibility to purchase them is inferential.

\section{Characteristics of family planning users:}

The current study results revealed characteristics of women currently use contraception are described in Table 2, currently used contraceptive methods were distributed as following about $44.1 \%$ use contraceptive pills, more than the quarter $(28.7 \%)$ use injections, $15.4 \%$ use IUD $8.7 \%$ use capsule and $3.1 \%$ use local methods as 81.5 are using hormonal methods. There was $51.8 \%$ of participant use another before the current one, these used methods were pills (14.9\%), injections (26.7\%), IUD (24.8\%), capsules $(8.9 \%)$ and local methods $(24.8 \%)$. Reasons for changing method are experiencing health problems $(60.4 \%)$, Contraceptive failure (19.8\%) and forgetting pills (19.8\%)

The current study results are in accordance with (18) who reported that, the percentage of using shortterm family planning methods including COC pills and injection (three months) was very elevated than invasive ones as the use of IUDs or implants.

${ }^{(19)}$ who studied "Determinants of low family planning use and high unmet need in Butajira District, South Central Ethiopia" reported that, oral contraception is the most preferred one among current users of contraception.

(4) reported that there was a recent change from the intrauterine device to the pill and indictable. The percentage of women depending on the intrauterine device decreased from sixty percent to fifty one percent at the period of 2008 till 2014. At the same time, the percentage of women depending on the oral contraceptive raised from twenty to twenty seven percent. A low elevation in the percentage of women depending on injection was noticed to be from twelve 
percent to fifteen percent. Researchers refer recent trend toward the use of hormonal methods including pills and injection as they are not invasive methods.

\section{Reasons for changing the method:}

The current study results revealedreasons for changing method are experiencing health problems (60.4\%), contraceptive failure (19.8\%) and forgetting pills $(19.8 \%)$

This is in accordance with ${ }^{(20)}$ who stated presence of barriers associated with the method itself, $63.2 \%$ of the discontinued women had a desire to have the more effective one. Also $36.1 \%$ had contraceptive failure. The most prominent cause was waiting for the menstruation to use the method (55.3\%). Also, 8.2\% of the discontinued women reported occurrence of severe bleeding as a serious complication.Regarding the reproductive barriers $54.6 \%$ of the discontinued women reported having side effects. Also, the most prominent side effects were related to menstrual changes.

(21), who studied "Family planning in a sub-district near Kumasi, Ghana: side effect fears, unintended pregnancies and misuse of a medication as emergency contraception" reported that users had a different experiences about contraception as one-third having feared of side effects of hormonal methods especially heart palpitations, as well as lack of knowledge or experience with specific domains for majority of contraception. Although, users desired to learn more about side effects and modern fertility awareness based methods. There is an imperative need for manipulations aimed at proper use of oral contraceptives, addressing the potential and actual health concerns of contraceptive methods through appropriate training family health nurses and fertility awareness regarding modern methods.

\section{Prevalence of recently occurred health problem:}

The present study results revealed that menstrual irregularities was the most prevalent (69.9\%) health problems among the studied females followed by headache $(54.6 \%)$, Nausea $(51.1 \%)$, followed by heart burn more than two fifth (42.9\%). vaginal discharge (38.3\%), mood changes (36.5\%) hypertension (34.8\%), on the other hand, the least reported ones were depression and $\mathrm{DM}(23.8 \%$ \& $3.9 \%)$ respectively.

These results is in agreement with ${ }^{(\mathbf{1 9})}$ stated that, about one fifth of participant women reported factors concerning the health problems and contradictions of family planning methods as, severe bleeding, heart pain and the assumption of their need of balanced diet suitable with work conditions.

Likewise, (22), who studied "contraceptive experience and perception, a survey among Ukrainian women" showed that future infertility was the most terrible experienced hormonal side effect as it reported by more than third of users, followed by thrombosis and weight gain as revealed by more than fifth of them. The limited use of hormonal methods was due to actual or feared side-effects.

In the same line, ${ }^{(21)}$, who summarized the common reasons of notusing aspecific contraceptivemethod. The most reported factor did not desire to use injectable or oral contraceptives due to its side effects as reported by about a third of them. Also, they were especially afraid of heart palpitation in case of using IUDs, injectable, or implants. Other reported side effectswere menstrual or weight fluctuation and vertigo with hormonal and that of IUDs or implants were painful insertion. Majority of participants described the particular side effects IUDs or implants as being feared, but others stated that they would be missed inside the body and diseased. Least of participants attributed permanent sterility to hormonal methods $(5.9 \%)$.

The current study results are similar to (23) that showedthe refusal of some participants to use contraception could be associated with anxiety of side effects. Also, women dislike invasive methods (IUD or implants) and of missing daily pill. Many of the side effects women reported, such as heart palpitations, vertigo, and changes of weight (decrease or increase) that may occur contraceptive methods.

The majority of women who use the birth control pill have no side-effects at all; while, some of them have mild side-effects such as spotting or bleeding, nausea, headache, tendered breast, weight changes, mood swings, low libido, and dermatologic problems. In fact, menstrual disturbances are the consequence of both the prevailing levels of estrogens and the more or less 
suppressed endometrium. Short-term studies have been suggested that combined hormonal methods may mildly elevate blood pressure ${ }^{(24)}$.

\section{Conclusion and Recommendation}

The current study revealed that contraceptive methods have important health impacts. Health states decrease the safeness and effectiveness of any contraceptive method. The effectiveness of contraception relies on its competent and proper use. Incompetent and improper use leads to many health problems and failed method. The most common health effects included menstrual irregularities, nauseas, headache and heart burn. Counseling for contraception should be introduced at affordable cost with improved quality of overall services to reduce health problems. Awareness should be raised by media and to be involving male contraceptives as a choice for selective criteria, medical free campaigns and social marketing contraceptive availability and its quality.

Conflict of Interests: There was no Conflict of Interests

Contributors: All authors contributed substantially to the study conception and design, data collection and analysis, and drafting and revision of the article. All approved the final version to be published.

Funding: Self.

\section{References}

1. Zafar, A., Asim, M., Gillani, I., Malik, N. The Impact of Contraceptive use on Women Health: A Study of District Rawalpindi, Pakistan. Academic Journal of Interdisciplinary Studies; 2013 Mar $1 ; 2(1), 257$.

2. Kantorová, V., Wheldon, M. C., Ueffing, P., Dasgupta, A. N. Estimating progress towards meeting women's contraceptive needs in 185 countries: A Bayesian hierarchical modelling study. PLoS medicine; 2020. 17(2), e1003026. ISO 690. Available from: https://doi.org/10.1371/ journal.pmed.1003026

3. World Health Organization. Family planning: a global handbook for providers; 2018. Available from: https://apps.who.int/iris/bitstream/hand le/10665/260156/9780999203705-eng.pdf.

4. El-Zanaty, F. Factors and determinants of FGM/C of girls aged 0-17 years: a secondary analysis of the Egypt demographic and health surveys, 2005, 2008 and 2014; 2015. UNICEF: Cairo. Available from :https://www.unicef.org/FGM_Secondary_ analysis_edited_5-08-2016_FINAL.pdf.

5. United Nations Development Program (UNDP), the Ministry of National Planning. Egypt's Progress towards Millennium Development Goals (MDGs). Background paper produced for the 2015 National Human Development Report. Cairo, Egypt; 2015. Available from http://www.hdr.undp.org/sites/ default/files/2015_human_development_report_0. pdf.

6. Khalifa, M., Abdelaziz, W., Sakr, E. Changes in contraceptive use dynamics in Egypt: analysis of the 2008 and 2014 demographic and health surveys. Rockville, Maryland, USA; 2017. 1-42. ICF. No. 132. Available from:https://dhsprogram.com/ publications/publication-wp132-working-papers. $\mathrm{cfm}$

7. Barden-O'Fallon, J., Speizer, I. S., Cálix, J., \& Rodriguez, F. An analysis of contraceptive discontinuation among female, reversible method users in urban Honduras. Studies in family planning; 2011. 42(1): 11-20. Available from: https://onlinelibrary.wiley.com/doi/abs/10.1111/ j.1728-4465.2011.00260.x

8. Polis, C. B., Bradley, S. E., Bankole, A., Onda, T., Croft, T., \& Singh, S. Contraceptive failure rates in the developing world: an analysis of demographic and health survey data in 43 countries. New York: Guttmacher Institute; 2016. Available from : https://www.guttmacher.org/sites/default/files/ report_pdf

9. Sayed, H. Abdel Aziz, W. Trends of Contraceptive Discontinuation and Switching in Egypt during 2000-2008; 2011. In Annual Conference of Statistics Department, Faculty of Economics and Political Sciences, Cairo University: Egypt. Available from: https://scholar.cu.edu. eg/sites/default/files/wafaaissr/files/trends_of_ contraceptive_discontinuation_and_switching_in egypt_during_2000-2008.pdf. 
10. Roudi-Fahimi, F., Monem, A. A., Ashford, L. O. R. I., El-Adawy, M. (2012). Women's need for family planning in Arab countries. Population Reference Bureau.1. Available from: https://arabstates. unfpa.org/en/publications/womens-need-familyplanning-arab-countries

11. Hassan, E. E., Ghazawy, E. R., Amein, N. M. Currently married women with an unmet need for contraception in Minia governorate, Egypt: profile and determinants. Open Journal of Preventive Medicine; 2017. 7(11), 225-234. Available from: https://www.scirp.org/html/1-1340566_80203.htm

12. United Nations, Department of Economic and Social Affairs. World Family Planning 2017-Highlights; 2017. Available from :https://www.un.org/en/ development/desa/population/publications/pdf/ family/WFP2017_Highlights.pdf.

13. Central Bank for Economic, Monopoly to the "birth control market" is causing the population to increase; 2018. [cited 2019 Jan 18] Available from https://www.almasryalyoum.com/news/ details/1362084.

14. Awadalla, H. I. Contraception use among Egyptian women: results from Egypt demographic and health survey in 2005. Journal of reproduction \& infertility; 2012. 13(3): 167-173. Available from: https://www.ncbi.nlm.nih.gov/pmc/articles/ PMC3719353/

15. Abdelhafez, A. A. Factors affecting the family planning methods used by the currently married women in rural Egypt. American journal of research communication; 2014. 2(10), 324-341. Available from : http://www.usa-journals.com/wp-content/ uploads/2014/09/Abdelhafez_Vol210.pdf

16. Achana, F. S., Bawah, A. A., Jackson, E. F., Welaga, P., Awine, T., Asuo-Mante, E., ...\& Phillips, J. F. Spatial and socio-demographic determinants of contraceptive use in the Upper East region of Ghana. Reproductive health; 2015. 12(1):1-10. Available from: https://reproductive-health-journal. biomedcentral.com/articles/10.1186/s12978-0150017-8

17. Nyarko, S. H. (2015). Prevalence and correlates of contraceptive use among female adolescents in Ghana. BMC women's health, 15(1); 1-6. DOI 10.1186/s12905-015-0221-2. Available from :https://link.springer.com/article/10.1186/s12905015-0221-2

18. Htun, K. W. W., Yodmai, K., \& Taechaboonsermsak, P.Emergency contraceptive pill use among women of reproductive age in Pathein, Myanmar. Journal of Health Research; 2019. 33(4): 349-358. Available from: https://www.emerald.com/insight/content/ doi/10.1108/JHR-07-2018-0047/full/html

19. Mekonnen, W., and Worku, A. Determinants of low family planning use and high unmet need in Butajira District, South Central Ethiopia. Reproductive health; 2011. 8(1): 37. Available from :https://doi. org/10.1186/1742-4755-8-37

20. Eltomy, E. M., Saboula, N. E., Hussein, A. A. Barriers affecting utilization of family planning services among rural Egyptian women.' EMHJEastern Mediterranean Health Region Journal. 2013;19(5):400-408. Available from: https://apps. who.int/iris/handle/10665/118367.

21. Krakowiak-Redd, D., Ansong, D., Otupiri, E., Tran, S., Klanderud, D., Boakye, I., and Crookston, B. Family planning in a sub-district near Kumasi, Ghana: side effect fears, unintended pregnancies and misuse of a medication as emergency contraception. African journal of reproductive health. 2011; 15(3):135-147. Available from :https://www.ajol.info/index.php/ajrh/article/ view/71444

22. Podolskyi,V.,Gemzell-Danielsson,K., andMarions, L. Contraceptive experience and perception, a survey among Ukrainian women. BMC women's health; 2018. 18(1): 1-6. Available from: https:// link.springer.com/article/10.1186/s12905-0180651-8

23. World Health Organization. Department of Reproductive Health, Research (WHO/RHR) and Johns Hopkins Bloomberg School of Public Health. Center for Communications Programs (CCP), Knowledge for Health Project. Family Planning: A global handbook for providers. Baltimore and Geneva: CCP and WHO/RHR; 2011. Available from: http://info. k4health. org/ globalhandbook. 
232 Medico-legal Update, July-September 2021, Vol.21, No. 3

24. Sabatini R, Cagiano R, Rabe T. Adverse effects of hormonal contraception. Journal fürReproduktionsmedizin und EndokrinologieJournal of Reproductive Medicine and
Endocrinology; 2011. 8(1): 130-156.

Available from: https://www.kup.at/journals/ summary/10167.html. 